\section{Misunderstanding about COPUS}

SIR - Your leading article about public understanding of science (Nature 374, $291-292 ; 1995)$ is misleading in relation to COPUS

COPUS (the Committee on the Public Understanding of Science of the Royal Society, British Association for the Advancement of Science and Royal Institution) was set up against a backdrop of considerable apathy and sometimes resistance from the scientific and other communities involved in science communication. It was set very general objectives by its founding bodies, perhaps modest but only with hindsight. This generality enabled COPUS to develop a broad programme of its own quite closely directed activities aimed at clearly defined and diverse target groups such as scientists and engineers themselves, government and civil servants, media, publishers, women and others. COPUS has also funded hundreds of other grassroots things and actively encouraged other bodies to do more too.

Over the ten years of COPUS's existence, many other bodies have also contributed greatly. What the White Paper did was to build on that effort and take it far beyond what one committee could ever have achieved on its own. Since then, the OST has continued to be active in pursuing its public understanding of science mission.

The aim of COPUS was never to stimulate the support of voters for basic research but to encourage the public's interest in science and to help people to take part in discussion on issues that affect their lives. A major goal has been to encourage scientists themselves to be more open and communicative.

Public understanding of science is not simple or someone would have cracked it by now. COPUS does have its limitations. We are well aware of this and commissioned an external evaluation of the programme to help us decide our future role. The report is just complete and COPUS will be responding over the next few weeks. Certainly COPUS needs to involve many more people in its discussions people who also need to know more about each other. A looser, more inclusive model must emerge that helps the debate of these important issues to develop in the United Kingdom. We have come a long way in raising public understanding of science as a matter for serious debate.

\section{Lewis Wolpert}

JIII A. Nelson

COPUS,

c/o The Royal Society,

6 Carlton House Terrace,

London SW1Y 5AG, UK

\section{Coloured slides}

SIR - There seem to me to be several good reasons for using blue projection slides (white letters on blue background) rather than black and white ${ }^{1}$. (1) Production is simple because, having made a negative, several blue copies can be made on different occasions using a simple ultraviolet (UV) light box and development in ammonia vapour (this may be necessary as they do fade with use), rather than wetcopying of negatives or contrast-reversal development of the original photographic film; (2) the intensity of blue, and hence to some extent the contrast, can be varied by length of UV exposure, being inversely related to exposure time; (3) if many slides are shown, blue and white is less tiring than black-white or white-black; and (4) they can be seen at low levels of ambient lighting while allowing enough light to take notes by. This last would of course also be true for black-on-white slides.

I have asked a number of colleagues, and the majority say they find blue a 'restful' colour, relaxing but not soporific; the manufacturers make similar sheet film that develops green, brown or red backgrounds, but these colours are not perceived as having the same authoritative calm as blue. I see no reason why the standards of the advertising industry should be applied to the exchange of scientific information, and do not believe that the increasing use of black text on white background on the computer screen has anything to do with the effectiveness of projection slides.

\section{John Tiffany}

Nuffield Laboratory of Ophthalmology, University of Oxford,

Walton Street, Oxford OX2 6AW, UK

SIR - Steiner $\emptyset$ vreb $\emptyset$ raises an interesting hare ${ }^{1}$. He tries to establish the preference of readers for black text on white background - against white on blue or diazo slides and computer screens. He cites research by IBM to corroborate his opinion. In reality, the truth is probably the reverse of what he claims.

By far the most common experimental finding in published books and journals is that silent reading from a screen is slower than reading from paper $^{2-6}$. The evidence is compelling and well documented. The doubt is in terms of the different experimental conditions. It is not clear, as Dillon ${ }^{7}$ points out, whether there is a generalizable effect, as subjects in the independent experiments referred to were treated with different stimulus materials. For example, Muter ${ }^{3}$ used white text on blue, whereas Gould and Grischkowsky ${ }^{5}$ used green text on a dark background.

Although the evidence refutes the IBM research referred to, there are other factors that may affect the choice of screen colour and screen fonts. It may be that silent reading is faster on paper, but one would have to know the answers to a number of questions. First, was the accuracy of reading affected? Did subjects show or report any fatigue? How did comprehension scores change over different treatments? Did subjects or readers express any subjective or aesthetic preference for one colour system over another?

$\emptyset_{\text {vreb } \emptyset \text { makes an interesting point, but }}$ such "commonsense theorizing" needs more rigorous examination. It is not sufficient to claim that "blue slides reduce readability and comprehension by about 20 per cent" without some backing and reproducible experimental findings.

\section{Ray McAleese}

Centre for Combined Studies,

Heriot-Watt University,

Edinburgh EH14 4AS, UK

1. Øvrebø, S. Nature 372, 494 (1994).

2. Kak, A. V. Proc. Human Factors Soc. 25 th Annual Meeting (Santa Monica, California, 1981).

3. Muter, P. etal. Human Factors 24, 501-508 (1982).

4. Smith, A. \& Savory, M. in Contemporary Ergonomics (ed Megaw, E. D.) (Taylor \& Francis, London, 1989).

Gould, J. \& Grischkowsky, N. Human Factors 28, 165-173 (1984).

6. Smedshammar. H. etal. Proc. WWDU 2nd int. Sci. Conf (Montreal, 1989).

7. Dillon, A. Designing Usabie Electronic Test (Taylor \& Francis, London, 1984).

\section{Adaptive events}

SIR - I take issue with John Godfrey's reasoning (Nature 373, 100; 1995) that "during this period [of fertilization, that takes about two days] genetic identity is yet to be established", and that it does not start with activation of egg, a process that "precedes the chromosomal events that establish the genetic identity of the zygote". It is unlikely that this process can start and evolve without any role played by that specific egg and that specific sperm. The evolution of the process will be determined by a variety of events and conditions, but the start of the process, that will result in an individual life, precedes the process itself and its marvellous complexity.

Godfrey claims that "even after the fusion of gametes stable individuality is some way off". But, when will stable individuality really be established during the process of human life? Every stage after birth is a series of continuous adaptative events, in which every cell in human tissues participates. Human individuality also derives from the function of nervous circuits that are changed by internal and external events. Thus, a stable individuality could never exist and no man or woman would be a stable individual person with rights and duties.

\section{Enzo Nisoli}

Department of Biomedical Sciences and Biotechnologies,

University of Brescia,

25123 Brescia, Italy 